\title{
HeartWare left ventricular assist device thrombosis including outflow graft
}

Ioannis Dimarakis, PhD, MRCS, Steven Shaw, PhD, MRCP, and Rajamiyer Venkateswaran, MD, FRCS (C-Th)

A 42-year-old man referred with refractory acute cardiogenic shock and ventricular arrhythmias after extensive anterior myocardial infarction underwent rescue implantation of a CentriMag (Levitronix LLC, Waltham, Mass) biventricular assist device. Because we were not able to match him with a suitable donor, he was implanted with a HeartWare left ventricular assist device (HeartWare International, Inc, Framingham, Mass). At 3 months after discharge, he was urgently readmitted with high pump flow, suggestive of pump thrombosis, for which he underwent thrombolysis. ${ }^{1,2}$ A subtherapeutic international normalized ratio of 1.6 had been documented 2 weeks before his presentation. However, the thrombolysis was complicated by subarachnoid hemorrhage from which the patient recovered without neurologic sequelae.

He was once again readmitted with high pump flow 11 months after device implantation, having been anticoagulated throughout with an international normalized ratio of 3.4 on admission. Furthermore, platelet mapping confirmed he was a responder to aspirin therapy. Computed tomography aortography depicted only a small amount of contrast entering the outflow graft near the aorta, and a previous study had demonstrated the entire length of the outflow graft opacifying (Figure 1). With knowledge of the extent of thrombus and additional thrombolysis not an option, we proceeded with pump exchange by way of redo sternotomy, replacing both the device and the outflow graft, which had become completely occluded by thrombus (Figure 2).

Pump thrombosis remains a dreaded complication for all mechanical assist implantation programs. Although our initial surgical planning included pump exchange by way of left thoracotomy with preservation of the original outflow graft, ${ }^{3}$ the preoperative imaging findings altered this plan, because it would have been impossible to replace the outflow graft. The patient recovered well and subsequently
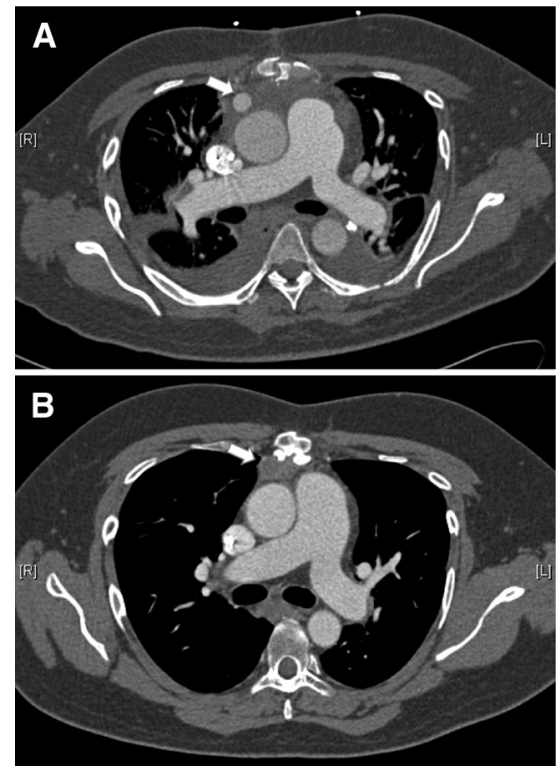

FIGURE 1. A and B, Axial sections of contrast computed tomography angiogram showing the outflow graft before joining the ascending aorta (arrows). B, No contrast could be seen entering the outflow graft on the most recent scan.

underwent left ventricular assist device explantation and cardiac transplantation.

\section{References}

1. Kiernan MS, Pham DT, DeNofrio D, Kapur NK. Management of HeartWare left ventricular assist device thrombosis using intracavitary thrombolytics. $J$ Thorac Cardiovasc Surg. 2011;142:712-4.

2. Goldstein DJ, John R, Salerno C, Silvestry S, Moazami N, Horstmanshof D, et al. Algorithm for the diagnosis and management of suspected pump thrombus. J Heart Lung Transplant. 2013;32:667-70.

3. Potapov EV, Stepanenko A, Kaufmann F, Henning E, Vierecke J, Lehmkuhl E, et al. Thrombosis and cable damage in the HeartWare pump: clinical decisions and surgical technique. ASAIO J. 2013;59:37-40.

\footnotetext{
From the Department of Cardiothoracic Surgery, University Hospital of South Manchester, Manchester, United Kingdom.

Disclosures: Authors have nothing to disclose with regard to commercial support.

Received for publication Nov 29, 2013; revisions received Jan 15, 2014; accepted for publication Jan 31, 2014; available ahead of print March 4, 2014.

Address for reprints: Ioannis Dimarakis, PhD, MRCS, Department of Cardiothoracic Surgery, University Hospital of South Manchester, Southmoor Rd, Wythenshawe, Greater Manchester M23 9LT, United Kingdom (E-mail: jdimarakis@nhs.net).

J Thorac Cardiovasc Surg 2014;148:1746-7

$0022-5223 / \$ 36.00$

Copyright (C) 2014 by The American Association for Thoracic Surgery

http://dx.doi.org/10.1016/j.jtcvs.2014.01.049
} 

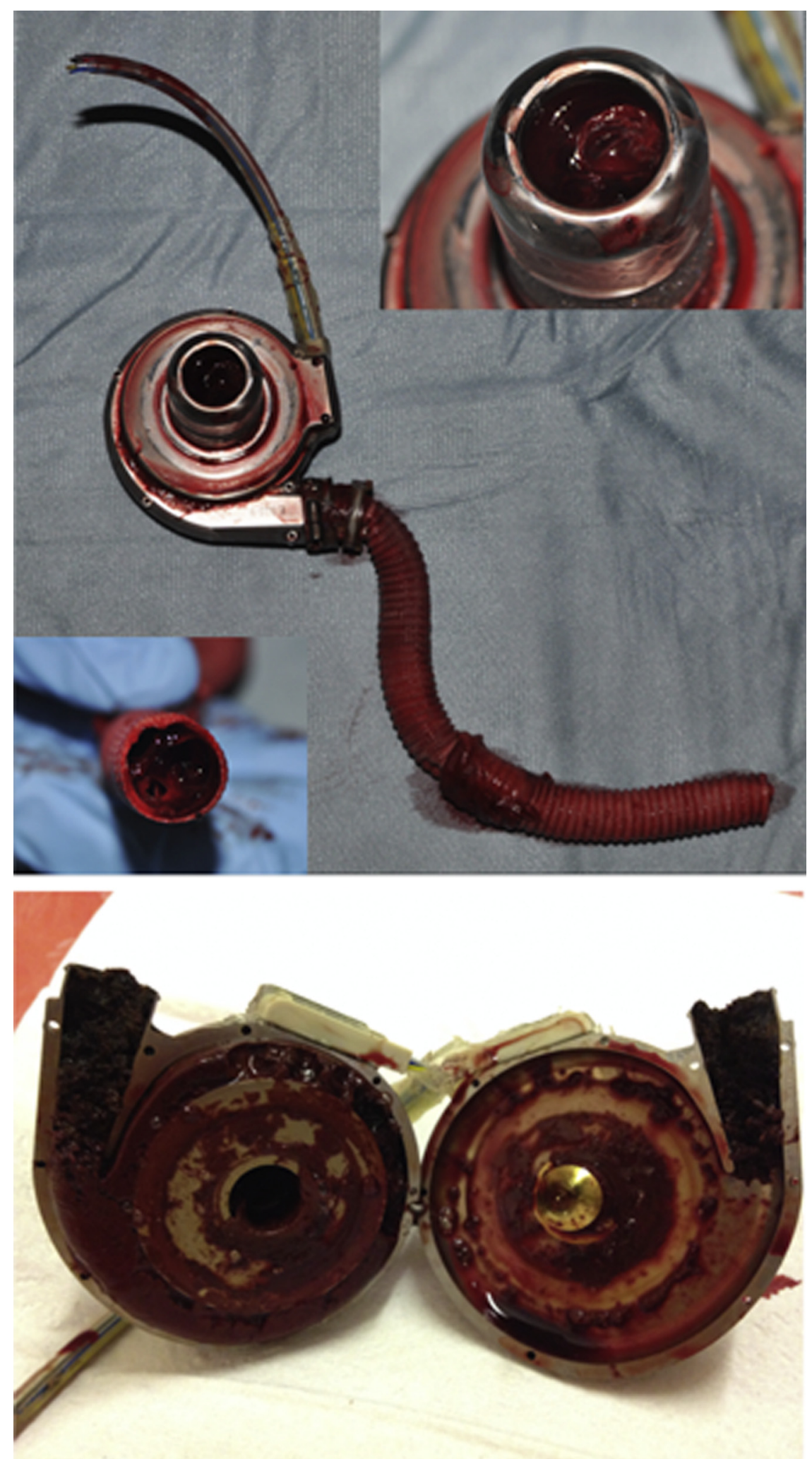

FIGURE 2. HeartWare left ventricular assist device after explantation with evidence of clot inside the device and occluding the entire length of the outflow graft. 